\title{
Synthetic Surfactant Based on Analogues of SP-B and SP-C Is Superior to Single-Peptide Surfactants in Ventilated Premature Rabbits
}

\author{
Andreas Almlén $^{\mathrm{a}}$ Frans J. Walther ${ }^{\mathrm{b}, \mathrm{c}}$ Alan J. Waring ${ }^{\mathrm{b}, \mathrm{d}}$ Bengt Robertson ${ }^{\mathrm{a}}$ \\ Jan Johansson ${ }^{\mathrm{e}}$ Tore Curstedt $^{\mathrm{a}}$ \\ a Department of Molecular Medicine and Surgery, Section of Clinical Chemistry, Karolinska Institutet, Karolinska \\ University Hospital, Stockholm, Sweden; ${ }^{b}$ Los Angeles Biomedical Research Institute, Harbor-University of \\ California at Los Angeles (UCLA) Medical Center, Torrance, Calif., USA; ${ }^{C}$ Department of Pediatrics, Leiden University \\ Medical Center, Leiden, The Netherlands; ${ }^{\mathrm{d}}$ Department of Medicine, UCLA School of Medicine, Los Angeles, Calif., \\ USA; ' Department of Anatomy, Physiology and Biochemistry, Swedish University of Agricultural Sciences, \\ The Biomedical Centre, Uppsala, Sweden
}

\section{Key Words}

Pulmonary surfactant $\cdot$ Synthetic surfactant $\cdot$ Surfactant protein B $\cdot$ Surfactant protein $C \cdot$ Synthetic peptide $\cdot$ Respiratory distress syndrome

\begin{abstract}
Background: Respiratory distress syndrome (RDS) is currently treated with surfactant preparations obtained from natural sources and attempts to develop equally active synthetic surfactants have been unsuccessful. One difference in composition is that naturally derived surfactants contain the two hydrophobic proteins SP-B and SP-C while synthetic preparations contain analogues of either SP-B or SP-C. It was recently shown that both SP-B and SP-C (or SP-C33, an SP-C analogue) are necessary to establish alveolar stability at end-expiration in a rabbit RDS model, as reflected by high lung gas volumes without application of positive end-expiratory pressure. Objectives: To study the efficacy of fully synthetic surfactants containing analogues of both SP-B and SP-C compared to surfactants with only one protein analogue. Methods: Premature newborn rabbits, treated with synthetic surfactants, were ventilated for $30 \mathrm{~min}$ without
\end{abstract}

\section{KARGER}

두 2010 S. Karger AG, Basel

Fax +41613061234 E-Mail karger@karger.ch www.karger.com www.karger.com/neo positive end-expiratory pressure. Tidal volumes as well as lung gas volumes at end-expiration were determined. $\boldsymbol{R} \boldsymbol{e}-$ sults: Treatment with $2 \%$ Mini-B (a short-cut version of SP-B) and $2 \%$ SP-C33, or its C-terminally truncated form SP-C30, in 1,2-dipalmitoyl-sn-glycero-3-phosphocholine/1-palmitoyl2-oleoyl-sn-glycero-3-phosphoglycerol, 68:31 (w/w) resulted in median lung gas volumes of $8-9 \mathrm{ml} / \mathrm{kg}$ body weight, while animals treated with $2 \%$ Mini-B surfactant or $2 \%$ SPC33/SP-C30 surfactant had lung gas volumes of $3-4 \mathrm{ml} / \mathrm{kg}$, and those treated with Curosurf, a porcine surfactant, 15-17 $\mathrm{ml} / \mathrm{kg}$. In contrast, mixing SP-C33 with peptides with different distributions of positively charged and hydrophobic residues did not improve lung gas volumes. Conclusions: The data indicate that synthetic surfactants containing analogues of both SP-B and SP-C might be superior to singlepeptide surfactants in the treatment of RDS.

Copyright $\odot 2010$ S. Karger AG, Basel 


\section{Introduction}

Respiratory distress syndrome (RDS) in preterm babies is today successfully treated by airway instillation of surfactant purified from animal lungs [1]. These preparations are expensive and have a limited supply and therefore there is a need for synthetic surfactant substitutes which can be produced in large quantities at low cost. However, pulmonary surfactant has a very complex composition consisting of the four surfactant-specific proteins SP-A, SP-B, SP-C and SP-D, and several species of phospholipids. SP-A and SP-D are mainly involved in host defense while SP-B and SP-C together with the lipids are responsible for the surface properties of surfactant [2-4].

Attempts to develop a synthetic pulmonary surfactant have met several difficulties. The greatest obstacle has been to synthesize the surfactant proteins SP-B and SP-C due to a metastable secondary structure (SP-C) and a complex tertiary structure (SP-B). Phospholipids are the main constituents of surfactant and 1,2-dipalmitoyl-snglycero-3-phosphocholine (DPPC) is the single most abundant species. SP-B and/or SP-C are important for optimal surfactant activity because of their ability to improve the reduction of surface tension mainly obtained by DPPC [3, 4].

SP-B and SP-C are structurally different. SP-C is a very hydrophobic lipoprotein which in its longest form has 35 amino acid residues and thioester-linked palmitoyl groups in the $\mathrm{N}$-terminal part [5]. The $\alpha$-helical part of the molecule is inserted in the lipid bilayer and orientated near parallel to the phospholipid acyl groups $[6,7]$. SP-B has 79 amino acid residues with seven Cys residues, forming three intramolecular disulfide bridges. The remaining Cys is linked to the corresponding residue of another SP-B monomer [8]. The homodimeric molecule may interact with the surface of lipid bilayers by means of four or five amphipathic $\alpha$-helices in each monomer. SP-B belongs to the saposin family of proteins, in which all members interact with lipids. The tertiary structures of several saposins have been determined and show 4- or 5helix bundles. The tertiary structures, however, differ between saposins since the helix packing varies significantly from closed [9] to open [10] conformations. The 3D structure of SP-B has not been determined, but SP-B differs from the other saposins by being a covalent dimer, and not being soluble in water. The apparently simple $\alpha$ helical structure of SP-C is not obtained in synthetic replicas, but recombinant SP-C, produced as a fusion protein, is helical $[11,12]$.
No method to produce the disulfide-bonded homodimeric structure of SP-B has been presented thus far. Attempts to overcome these problems have included design of SP-B and SP-C analogues [13]. Analogues, structural and/or functional, have been included in different phospholipid mixtures and evaluated in both premature animals with surfactant deficiency [14-21] and in adult animals with experimental acute respiratory distress syndrome [22-26]. All synthetic surfactants analyzed so far have contained a single peptide or peptoid, being designed to mimic SP-B or SP-C, mixed with comparatively simple lipid mixtures. Some of these preparations have shown activity similar to natural derived surfactant preparations as regards increased lung compliance in animal models of RDS. However, alveolar stability at end-expiration has been inferior to what is obtained by treatment with natural derived surfactants, as measured by requirement of ventilation with a positive end-expiratory pressure (PEEP) or lower lung gas volumes, reflecting the functional residual capacity, in the absence of PEEP [15, $17,27]$.

The quality of an exogenous surfactant is dependent on both its ability to increase lung compliance and to stabilize the alveoli at end-expiration. For proper evaluation of the latter function, animal experiments need to be performed without PEEP, since PEEP will at least to some degree prevent alveolar collapse at end-expiration and hence make it difficult to differentiate between exogenous surfactants of optimal and medium quality [17]. Recently we found that addition of porcine SP-B to a synthetic surfactant composed of the analogue SP-C33 mixed with DPPC/1-palmitoyl-2-oleoyl-sn-glycero-3-phosphoglycerol (POPG), 68:31 (w/w) (SP-C33 surfactant) resulted in increased lung gas volumes in premature newborn rabbit ventilated without PEEP [28]. This indicates that SP-B and SP-C fulfill different functions and that both proteins are required to prevent alveolar collapse at the end of expiration.

In the present study, using the premature rabbit model, we have investigated whether Mini-B [29] and two model peptides with primary structures different from SP-B may work as a functional SP-B analogue when added to SP-C33 surfactant. SP-C33 is a full-length protein analogue of SP-C that retains the transmembrane helical domain by substituting leucines for valines and has serines replacing the palmitoylated cysteines in the $\mathrm{N}$ terminal segment of the protein (fig. 1a). As shown in figure $1 b$, Mini-B is a 'truncated' analogue of SP-B in which the positively charged $\mathrm{N}$-terminal amphipathic helix is connected to the positively charged C-terminal 
Fig. 1. a Molecular graphics illustration of SP-C33 in methanol based on the structure of native porcine SP-C (1SPF). Helical residues in the transmembrane sequence are in red, the $\mathrm{N}$-terminal serine residues are in yellow, and disordered segments are in green. b Mini-B structure in methanol based on the structure of Mini-B (1SSZ) with the helical segments in red, the engineered loop in green and the disulfide linkages in yellow.

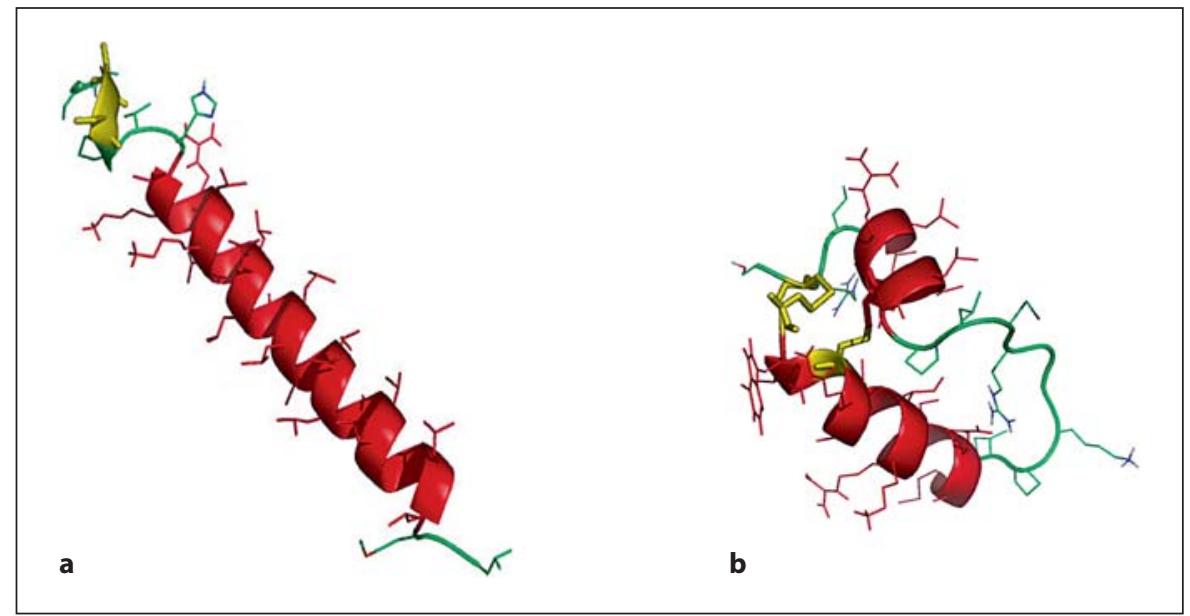

amphipathic helix by an engineered loop and it contains two intrachain disulfide bridges present in SP-B [30] (fig. 1b).

\section{Materials and Methods}

Lipids and Polypeptides

DPPC and POPG were obtained from Sigma Chemical (St. Louis, Mo., USA).

SP-C33 (IPSSPVHLKRLKLLLLLLLLILLLILGALLMGL) was provided by Chiesi Farmaceutici SpA (Parma, Italy). SP-C33 has a modified sequence compared to human SP-C [17].

SP-C30 (IPSSPVHLKRLKLLLLLLLLILLLILGALL) is a Cterminally truncated version of SP-C33, and was obtained from Thermo Fisher Scientific (Ulm, Germany).

Mini-B (CWLCRALIKRIQAMIPKGGRMLPQLVCRLVLRCS), with Cys1-Cys33 and Cys4-Cys27 linkages, was synthesized using a FastMoc protocol as described previously, HPLC purified, folded and air oxidized in trifluoroethanol:buffer [29]. Mini-B positions 1-18 represent human SP-B positions 8-25 and positions 19-34 in Mini-B represent human SP-B positions 63-78.

The peptide $\mathrm{KL}_{2,3}$ (LLLKLLKLLLKLLKLLLKLLL) was synthesized and purified as described previously for other helical peptides [16] whereas $\mathrm{KLK}_{3}$ (LLKLKLLLLLLLKLKLLLLLLLKLKLL) was obtained from Thermo Fisher Scientific.

Porcine SP-B was isolated from Curosurf paste using size exclusion chromatography over a LH-20 resin in chloroform/methanol as described [28].

\section{Surfactant Preparations}

DPPC/POPG (68:31, w/w) was dissolved in chloroform:methanol $(1: 1, v / v)$ and mixed with SP-C33, SP-C30, Mini-B, porcine SP-B, $\mathrm{KL}_{2,3}, \mathrm{KLK}_{3}$, or combinations thereof, in the same solvent. The peptide content in the preparations was 1 or $2 \%$ of each peptide in relation to the phospholipid weight. The solvents were evaporated with nitrogen and the preparations were resuspended in saline to a final phospholipid concentration of $80 \mathrm{mg} / \mathrm{ml}$ by slow rotation at $37^{\circ} \mathrm{C}$. The preparations were stored at $-20^{\circ} \mathrm{C}$. Be- fore examinations in vitro, all solutions were diluted in saline to a final phospholipid concentration of $10 \mathrm{mg} / \mathrm{ml}$.

\section{In vivo Experiments}

The pregnant rabbit does were sedated and anesthetized by intramuscular injections of diazepam (Stesolid $\left.{ }^{\circledR}\right), 5 \mathrm{mg} / \mathrm{kg}$, and fentanyl citrate/fluanisone (Hypnorm ${ }^{\circledR}$ ), $0.3 \mathrm{ml} / \mathrm{kg}$. Preterm newborn rabbits obtained by hysterotomy at a gestational age of 27 days (term 31 days), were anesthetized with intraperitoneal sodium pentobarbital, $25 \mathrm{mg} / \mathrm{kg}$, and tracheotomized at birth. The animals were randomly allocated to different treatments and $2.5 \mathrm{ml} / \mathrm{kg}$ of surfactant, $80 \mathrm{mg} / \mathrm{ml}$, was administered via a tracheal cannula at a total dose of $200 \mathrm{mg} / \mathrm{kg}$. Animals receiving the same dose of Curosurf served as positive controls and nontreated littermates as negative controls. The animals were kept in plethysmograph boxes at $37^{\circ} \mathrm{C}$ and ventilated in parallel with $100 \%$ oxygen at a frequency of $40 / \mathrm{min}$ and an inspiration/expiration ratio 1:1. Peak inspiratory pressure was first set at $35 \mathrm{~cm}$ $\mathrm{H}_{2} \mathrm{O}$ for $1 \mathrm{~min}$ in order to open up also the lungs of the nontreated controls. Then pressure was lowered to $25 \mathrm{~cm} \mathrm{H}_{2} \mathrm{O}$ for 15 min and further on to $20 \mathrm{~cm} \mathrm{H}_{2} \mathrm{O}$ for $5 \mathrm{~min}$ and $15 \mathrm{~cm} \mathrm{H}_{2} \mathrm{O}$ for $5 \mathrm{~min}$. Finally, pressure was raised again to $25 \mathrm{~cm} \mathrm{H}_{2} \mathrm{O}$ for $5 \mathrm{~min}$ after which the lungs were ventilated for additional $5 \mathrm{~min}$ with nitrogen. The pressure changes are included to determine the surfactant effect on the tidal volumes at lower pressures and the capability of surfactant to reopen the lung after a period with low tidal volumes, while the nitrogen ventilation at the end of experiment was included to prevent oxygen diffusion into the lungs and thus allow accurate determination of lung gas volumes. The experiments were performed without PEEP. Tidal volumes were recorded every $5 \mathrm{~min}$. At the end of the experiment the tracheal cannula was clamped at end-expiration, the trachea ligated, and the lungs were excised and weighed. Lung gas volumes were determined by water displacement technique as described [28, 31].

\section{Lung Histology}

The lungs were fixed by immersion in $4 \%$ neutral formalin, dehydrated and embedded in paraffin. Transverse sections, stained with hematoxylin and eosin, were examined by light mi- 


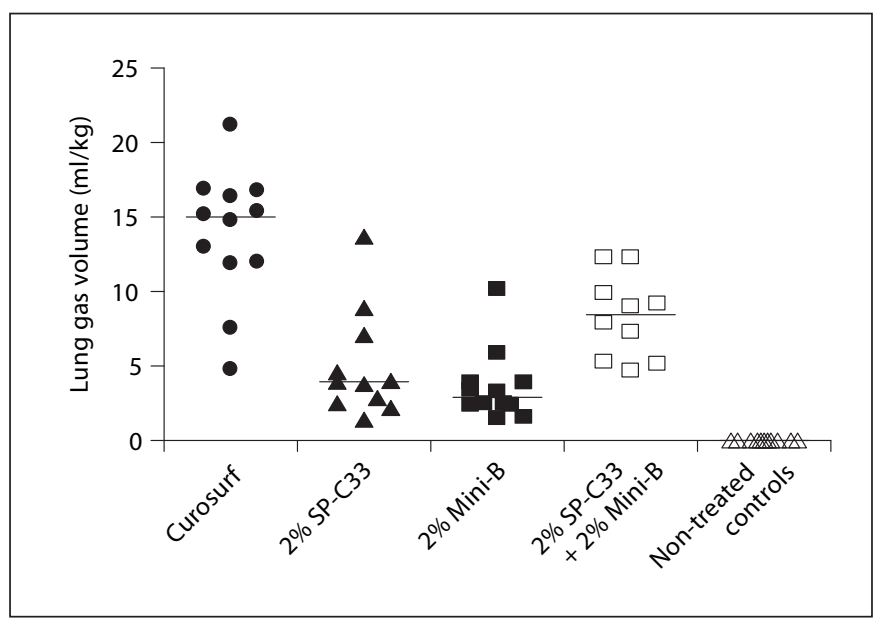

Fig. 2. Lung gas volumes in preterm newborn rabbits treated with surfactants containing SP-C33 + Mini-B, Mini-B, SP-C33, or Curosurf, and in non-treated controls. Two percent of each of the synthetic peptides were mixed with DPPC/POPG (68:31, w/w). All surfactants were administered at a dose of $80 \mathrm{mg}$ phospholip$\mathrm{ids} / \mathrm{ml}, 2.5 \mathrm{ml} / \mathrm{kg}$. Levels of statistical significance: Curosurf: $\mathrm{p}<$ 0.0005 vs. all other groups; $2 \%$ SP-C $33+2 \%$ Mini-B: $\mathrm{p}<0.02$ vs. 2\% SP-C33, 2\% Mini-B and non-treated controls, respectively. $2 \%$ SP-C33: $\mathrm{p}<0.001$ vs. non-treated controls. $2 \%$ Mini-B: $\mathrm{p}<0.005$ vs. non-treated controls. The lines indicate median values.

croscopy with particular reference to alveolar expansion and airway epithelial necrosis. The proportion of well-aerated alveoli was estimated and classified semiquantitatively according to a 5grade scale $(0: 0,1: 1-25,2: 26-50,3: 51-75,4:>75 \%)$ while a 4 grade score was used for estimation of airway epithelial necrosis $(0=$ absent, $1=$ mild, $2=$ moderate, $3=$ prominent $)$. In addition, alveolar volume density $\left(\mathrm{V}_{\mathrm{v}}\right)$ was measured with a computer-aided image analyzer using total parenchyma as reference volume [32].

\section{Molecular Graphics}

The models of SP-C33 and Mini-B used the protein backbone structure of the lowest energy conformers of porcine SP-C (PDB $1 \mathrm{SPF})$ and Mini-B (PDB 1SSZ) as molecular templates. The sequences were aligned and homology modeled with Modeller version 9v4 (http://www.salilab.org/modeller/). The SP-C33 and Mini-B structures were further refined using the Gromacs suite of molecular dynamics programs [33]. The homology structure was placed in a periodic 80 cubic $\AA$ box of methanol to emulate an environment of intermediate polarity similar to surfactant phospholipids, minimized by the steepest descent method as implemented, the solvent pre-equilibrated for 100 ps and the system then subjected to $10 \mathrm{~ns}$ of molecular dynamics at $300 \mathrm{~K}$ in the GROMACS version 3.3 environment [33; http://www.gromacs. org] to obtain a final structural approximation of the peptides.

\section{Statistics}

One-way ANOVA was followed by the Newman-Keuls multiple comparison test for the in vivo data. Histological scores were

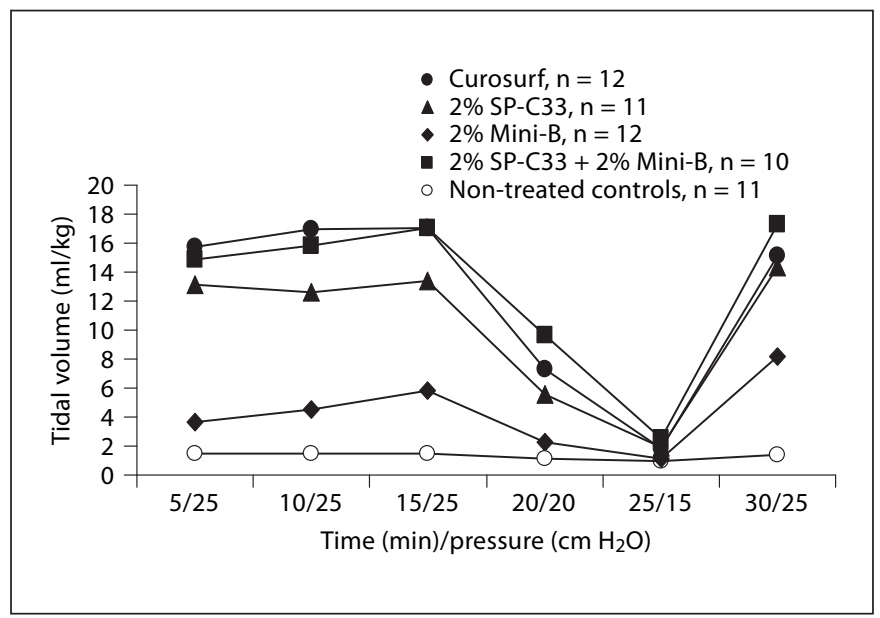

Fig. 3. Tidal volumes in preterm newborn rabbits treated with surfactants containing 2\% SP-C33 + 2\% Mini-B, 2\% Mini-B, 2\% $\mathrm{SP}-\mathrm{C} 33$, or Curosurf, and in non-treated controls (see figure 2 for details). No significant differences were observed between Curosurf, 2\% SP-C33 and 2\% SP-C33 + 2\% Mini-B. These groups had significantly higher tidal volumes than non-treated controls (at 5-20 and $30 \mathrm{~min}$ ) and the 2\% Mini-B group (at 5-15 min) $(\mathrm{p}<$ $0.05-0.001)$. Non-treated controls and $2 \%$ Mini-B were significantly different only at $30 \mathrm{~min}(\mathrm{p}<0.05)$. The results are given as median values.

analyzed by one-way ANOVA, non-parametric as described by Kruskal-Wallis, and followed by Dunn's multiple comparison post-test. Statistical significance was considered when $p<0.05$. The data were statistically evaluated using Statistica (Statsoft, Inc., Tulsa, Okla., USA).

Ethics

The animal experiments were approved by the local ethical committee for animal research, Stockholms norra Djurförsöksetiska Nämnd (316/06).

\section{Results}

The efficacy of $2 \%$ each of Mini-B + SP-C33, 2\% Mini-B, 2\% SP-C33, all combined with DPPC/PPOPG, $68: 31(w / w)$, and Curosurf was compared in premature newborn rabbits. After $30 \mathrm{~min}$ of ventilation without PEEP, animals treated with SP-C33 + Mini-B surfactant had lung gas volumes of about $8 \mathrm{ml} / \mathrm{kg}$, which is significantly higher than the 3-4 $\mathrm{ml} / \mathrm{kg}$ obtained for the preparations containing either SP-C33 or Mini-B, but inferior to the about $15 \mathrm{ml} / \mathrm{kg}$ obtained in animals treated with Curosurf (fig. 2). Animals treated with Mini-B + SP-C33, Curosurf, or SP-C33 surfactants had similar 
Table 1. Histological observations in preterm newborn rabbits treated with $2 \%$ Mini-B, 2\% SP-C33, $2 \%$ Mini-B $+2 \%$ SP-C33, all in DPPC/POPG (68:31, w/w), Curosurf, or non-treated controls ${ }^{\mathrm{a}}$

\begin{tabular}{lllll}
\hline Treatment & $\mathrm{n}$ & $\begin{array}{l}\text { Grade of expansion } \\
(0-4)\end{array}$ & $\begin{array}{l}\text { Epithelial necrosis } \\
(0-3)\end{array}$ & $\begin{array}{l}\text { Alveolar volume } \\
\text { density }(\%)\end{array}$ \\
\hline Curosurf & 12 & $3(1-3)^{*}$ & $1(0-1)^{\#}$ & $64(52-71)^{* *, * * *}$ \\
$2 \%$ SP-C33 & 11 & $1(0-2)^{\#}$ & $1(0-2)$ & $53(49-57)$ \\
$2 \%$ Mini-B & 12 & $1(0-2)^{\#}$ & $1(0-2)$ & $52(38-59)$ \\
$2 \%$ SP-C33 + 2\% Mini-B & 10 & $2(1-3)^{\# \#, \mathrm{x}, \S}$ & $1(0-2)$ & $58(50-65)^{\mathrm{x}, \S}$ \\
Non-treated controls & 11 & $0(0-1)$ & $1.5(1-3)$ & $57(48-62)$ \\
\hline
\end{tabular}

Values are given as median (range). $\mathrm{n}=$ Number of animals.

${ }^{a}$ All surfactants were administered at a dose of $80 \mathrm{mg}$ phospholipid $/ \mathrm{ml}, 2.5 \mathrm{ml} / \mathrm{kg}$.

${ }^{*} \mathrm{p}<0.01$ vs. all other groups; ${ }^{* *} \mathrm{p}<0.02$ vs. $2 \%$ SP-C $33+2 \%$ Mini-B; ${ }^{* *} \mathrm{p}<0.001$ vs. $2 \%$ SP-C $33,2 \%$ Mini$\mathrm{B}$ and non-treated controls, respectively.

${ }^{\#} \mathrm{p}<0.05$ vs. non-treated controls; ${ }^{\# \#} \mathrm{p}<0.01$ vs. non-treated controls.

${ }^{\mathrm{x}} \mathrm{p}<0.01$ vs. $2 \%$ Mini-B.

${ }^{\S} \mathrm{p}<0.05$ vs. $2 \%$ SP-C33.

tidal volumes (fig. 3). Animals treated with Mini-B surfactant had lower tidal volumes than the other surfactant-treated animals throughout the 30 -min ventilation period, except at the lowest pressure of $15 \mathrm{~cm} \mathrm{H} \mathrm{H}_{2} \mathrm{O}$ (fig. 3). Histologically, animals treated with Curosurf showed a significantly higher grade of alveolar expansion than all other groups, and those receiving Mini-B + SP-C33 had better lung expansion than the singlepeptide mixtures (table 1). No significant difference was seen between the groups treated with SP-C33 or Mini-B alone. Regarding epithelial necrosis, all surfactanttreated groups showed similar behavior, but only the Curosurf-treated animals showed statistically significant less necrosis than non-treated controls (table 1). In surfactant-treated animals, tidal volumes at $30 \mathrm{~min}$ were not correlated to lung gas volumes $(r=0.28, \mathrm{p}>0.05)$ or alveolar volume densities $(\mathrm{r}=0.04, \mathrm{p}>0.05)$, while a positive correlation was observed between lung gas volumes and alveolar volume densities $(\mathrm{r}=0.84, \mathrm{p}<0.05)$ indicating that tidal volume and lung gas volume/alveolar volume density measure different surfactant properties.

Reducing the amounts of Mini-B and SP-C33 to $1 \%$ each in the same phospholipid mixture as used above resulted in no improvement of lung gas volumes and alveolar expansion, measured as alveolar volume density, compared to SP-C33-treated animals and both surfactant mixtures gave clearly inferior values compared to those obtained after treatment with Curosurf (table 2). Addition of $1 \%$ of porcine SP-B to $1 \%$ of SP-C33 surfac- tant increased lung gas volumes and tidal volumes but the improvements were not statistically significant (table 2).

Next, the in vivo efficacy of SP-C30, a three-residue C-terminally truncated version of SP-C33, mixed with Mini-B was investigated. Two percent each of SP-C30 and Mini-B in DPPC/POPG, 68:31 (w/w), gave lung gas volumes of $9 \mathrm{ml} / \mathrm{kg}$, which was significantly higher than the about $4 \mathrm{ml} / \mathrm{kg}$ for SP-C30 surfactant (table 2). These results correlated with the alveolar volume densities (table 2). The tidal volumes after $30 \mathrm{~min}$ of ventilation for Mini-B + SP-C30 surfactant, and SP-C30 surfactant, were significantly lower than for Curosurf (table 2).

Mixing 2\% each of the peptides $\mathrm{KL}_{2,3}$ and SP-C33 in DPPC/POPG, 68:31 (w/w), resulted in lung gas volumes of about $5 \mathrm{ml} / \mathrm{kg}$, and surfactants containing one of the peptides only also gave lung gas volumes of about $5 \mathrm{ml} /$ $\mathrm{kg}$ (table 2). Tidal volumes for $\mathrm{KL}_{2,3}+\mathrm{SP}-\mathrm{C} 33$ and SPC33 only surfactants were similar (table 2). In a similar manner, mixing the peptide $\mathrm{KLK}_{3}$ with SP-C33 in DPPC/POPG 68:31 (w/w) resulted in lung gas volumes of about $6-7 \mathrm{ml} / \mathrm{kg}$, similar to surfactants containing $\mathrm{KLK}_{3}$ only, and SP-C33 only surfactant gave $3 \mathrm{ml} / \mathrm{kg}$ (table 2). Addition of $\mathrm{KL}_{2,3}$ or $\mathrm{KLK}_{3}$ to SP-C33 surfactant had no significant effect on alveolar volume density (table 2). Tidal volumes after $30 \mathrm{~min}$ of ventilation were similar for all surfactant-treated groups (table 2). 
Table 2. Tidal volumes, lung gas volumes and alveolar volume density in preterm newborn rabbits treated with $200 \mathrm{mg} / \mathrm{kg}(80 \mathrm{mg} / \mathrm{ml})$ of DPPC/POPG (68:31, w/w) mixed with peptides

\begin{tabular}{|c|c|c|c|c|}
\hline Treatment & $\mathrm{n}$ & $\begin{array}{l}\text { Tidal volume } \\
\mathrm{ml} / \mathrm{kg}\end{array}$ & $\begin{array}{l}\text { Lung gas volume } \\
\mathrm{ml} / \mathrm{kg}\end{array}$ & $\begin{array}{l}\text { Alveolar volume } \\
\text { density (\%) }\end{array}$ \\
\hline $1 \%$ SP-C33 & 15 & $9.9(1.7-20.4)$ & $4.7(1.8-8.0)$ & $52(44-61)$ \\
\hline $1 \%$ SP-C33 + 1\% SP-B & 14 & $13.2(1.2-26.1)$ & $8.2(2.0-11.9)$ & $55(49-61)$ \\
\hline $1 \%$ SP-C33 + 1\% Mini-B & 14 & $5.6(1.4-23.2)$ & $5.1(2.6-10.3)$ & $54(38-63)$ \\
\hline Curosurf & 13 & $8.8(1.4-28.3)$ & $18.2(7.8-36.0)^{+}$ & $68(50-74)^{+}$ \\
\hline Non-treated controls & 14 & $1.1(0.6-2.5)^{*}$ & $0.4(0-2.0)^{* * * * *}$ & $51(41-56)$ \\
\hline $2 \% \mathrm{SP}-\mathrm{C} 30$ & 8 & $7.0(3.3-9.6)$ & $4.1(2.4-7.3)^{\#}$ & $53(42-64)$ \\
\hline $2 \%$ SP-C30 + $2 \%$ Mini-B & 8 & $9.7(4.1-16.6)^{\#}$ & $9.0(7.3-11.7)^{!}$ & $63(56-67) ! !$ \\
\hline Curosurf & 8 & $18.7(2.9-37.1)^{\# \#}$ & $16.5(9.4-24.2)^{+}$ & $68(58-73) ! ! !$ \\
\hline Non-treated controls & 8 & $1.3(1.1-1.5)$ & $1.6(0.3-1.7)$ & $50(45-56)$ \\
\hline $2 \%$ SP-C33 & 6 & $17.6(8.4-22.4)$ & $5.1(3.9-9.9)$ & $53(47-63)$ \\
\hline $2 \% \mathrm{KL}_{2,3}+2 \% \mathrm{SP}-\mathrm{C} 33$ & 7 & $15.3(6.7-30.5)$ & $5.3(2.5-6.5)$ & $56(54-61)$ \\
\hline Curosurf & 5 & $23.8(12.5-30.2)$ & $23.4(10.4-24.3)^{+}$ & $69(62-78)^{+}$ \\
\hline Non-treated controls & 4 & $1.0(0.7-2.4)^{*}$ & $1.4(0-1.6)$ & $55(54-58)$ \\
\hline $2 \%$ SP-C33 & 11 & $13.5(4.3-20.0)$ & $3.3(0.7-6.4)$ & $52(45-64)$ \\
\hline $2 \% \mathrm{KLK}_{3}$ & 11 & $13.4(6.2-22.7)$ & $6.4(4.0-7.7)$ & $56(44-64)$ \\
\hline $2 \% \mathrm{KLK}_{3}+2 \% \mathrm{SP}-\mathrm{C} 33$ & 11 & $17.7(4.6-23.1)$ & $6.5(2.0-13.9)$ & $58(45-76)$ \\
\hline Curosurf & 10 & $13.0(6.0-31.0)$ & $20.5(8.1-36.2)^{+}$ & $71(58-77)^{+}$ \\
\hline Non-treated controls & 11 & $1.4(0-13.4)^{+}$ & $0.7(0-3.3)^{+}$ & $52(46-60)$ \\
\hline
\end{tabular}

Values are given as median (range). $\mathrm{n}=$ Number of animals.

Tidal volumes were measured after $30 \mathrm{~min}$ of ventilation at an insufflation pressure of $25 \mathrm{~cm} \mathrm{H}_{2} \mathrm{O}$. Positive controls were treated with Curosurf $(80 \mathrm{mg} / \mathrm{ml}, 200 \mathrm{mg} / \mathrm{kg})$ and non-treated animals were used as negative controls.

${ }^{*} \mathrm{p}<0.01$ vs. all surfactants; ${ }^{* *} \mathrm{p}<0.05$ vs. $1 \%$ SP-C33 $+1 \%$ Mini-B; ${ }^{* * *} \mathrm{p}<0.05-0.01$ vs. $1 \%$ SP-C33 and $1 \%$ SP-C33 + 1\% SP-B.

${ }^{\#} \mathrm{p}<0.05$ vs. non-treated controls; ${ }^{\# \#} \mathrm{p}<0.02$ vs. all other groups.

$+\mathrm{p}<0.0005$ vs. all other groups.

! $\mathrm{p}<0.02$ vs. $2 \%$ SP-C30 and non-treated controls; !" p < 0.01 vs. $2 \%$ SP-C30 and non-treated controls; "!! $\mathrm{p}<$ 0.0005 vs. $2 \%$ SP-C30 and non-treated controls.

\section{Discussion}

Premature infants with RDS are routinely treated with airway instillation of surfactant extracted from animal lungs and the covalent structures of SP-B and SP-C are known $[34,35]$. In spite of these advances, attempts to formulate a synthetic surfactant have not yet resulted in a preparation which is comparable to naturally derived surfactants. Herein we addressed the question whether synthetic analogues of both SP-B and SP-C, in mixture with DPPC/POPG, 68:31, give a better response in an RDS model in which premature rabbit fetuses are ventilated without PEEP, than preparations containing only one of the analogues. Surfactant preparations containing only SP-C33, or porcine SP-C, are sufficient to give adequate tidal volumes in the rabbit RDS model. However, the inclusion of porcine SP-B improves lung gas volumes, suggesting that this experimental model can be used to identify SP-B analogues, which in combination with SPC33 give an optimal synthetic surfactant [28]. The present study is the first one that investigates a fully synthetic surfactant containing analogues of both SP-B and SP-C.

Mini-B is a structural analogue of SP-B. It represents a 'short-cut' version of human SP-B in which the first helix has been connected to the last helix via a structurally unordered loop [30]. Addition of 2\% Mini-B to 2\% SPC33 in DPPC/POPG, 68:31 (w/w), improved both lung gas volumes (fig. 2) and alveolar expansion (table 1) but only small changes in tidal volumes compared to SP-C33 surfactant were observed (fig. 3). Since no significant correlation was observed between tidal volumes and lung gas 
volumes in surfactant-treated animals, the methods seem to measure different surfactant functions. A C-terminally truncated SP-C analogue, SP-C30, combined with Mini-B, also improved lung gas volumes and alveolar expansion measured as alveolar volume density (table 2). This shows that Mini-B possesses functions similar to those of SP-B and that, in the animal model used, a synthetic surfactant containing Mini-B and SP-C33/SP-C30 is superior to surfactants with only one of these analogues. However, addition of $1 \%$ Mini-B to $1 \%$ SP-C33 in DPPC/POPG, $68: 31(\mathrm{w} / \mathrm{w})$, or adding $1 \%$ of porcine SP-B to $1 \% \mathrm{SP}-\mathrm{C} 33$ in the same lipid mixture did not significantly increase lung gas volumes and alveolar expansion (table 2). Tidal volumes in animals treated with Mini-B surfactant are lower than in animals treated with Mini-B + SP-C33 surfactant, SP-C33 surfactant (fig. 3), or porcine SP-B in DPPC/POPG, 68:31 (w/w) [28]. These results suggest that Mini-B does not fully mimic native SP-B. This is not unexpected since the ability to interact with phospholipids is different between SP-B and Mini-B. Native SP-B is a disulfide-linked dimer with a mass of 17 $\mathrm{kDa}$, while Mini-B has a mass of $3.9 \mathrm{kDa}$, and their threedimensional structures and surface properties are expected to differ as well. These findings are in line with the observation that Mini-B mixed with phospholipase-resistant lipids has somewhat lower surface activity in vitro than a modified natural surfactant [36].

Mini-B dissolved in SDS micelles has an amphiphilic character; one side exposes mainly basic side chains and another side exposes mainly hydrophobic side chains [30]. We therefore tested whether inclusion of $2 \%$ of the peptide $\mathrm{KL}_{2,3}$, which forms a basic/hydrophobic amphipathic $\alpha$-helix, or $2 \%$ of the peptide $\mathrm{KLK}_{3}$, which contains three clusters of basic residues separated by two 7residue segments of hydrophobic residues, had any effect on SP-C33 surfactant. None of the peptides resulted in improved lung gas volumes or alveolar expansion, compared to the single-peptide counterparts (table 2). This shows that the superior effects of Mini-B + SP-C33/SPC30 surfactants are not caused by increased total peptide contents and agrees with our previous observation that animals receiving 4\% of SP-C33 in DPPC/POPG, 68:31 $(w / w)$, have virtually identical lung gas volumes as those receiving the corresponding surfactant with $2 \%$ SP-C33 [28]. The data shown in figure 2 and table 2 strongly suggest that Mini-B possesses features which cannot easily be mimicked by more simple peptides.

The present results are encouraging for the development of a fully synthetic surfactant that can be used in replacement therapy. However, the lung gas volumes achieved by Curosurf treatment are clearly superior compared to any of the synthetic mixtures now analyzed (fig. 2; table 2). Our recent observation that mixtures of porcine SP-B and SP-C in DPPC/POPG, 68:31 (w/w), are also inferior to Curosurf [28] suggests that the lipid composition, rather than the surfactant protein analogues, needs to be improved. The lipid mixture preparations obtained by extraction of natural surfactant are very complex and contain at least 50 different species in widely varying amounts. Compared to this, phospholipid mixtures in synthetic surfactant preparations are primitive. More complex lipid mixtures have been investigated [25, 37], but they are still far from the complexity of modified natural surfactants and their impact on the ability to establish high lung gas volumes in the absence of PEEP remains unknown.

Our present data indicate considerable variability in the physiological response to surfactant therapy which is in agreement with clinical observations [38]. After 30 min of ventilation, tidal volumes of Curosurf-treated animals ranged from 1.4 to $37.1 \mathrm{ml} / \mathrm{kg}$ and lung gas volumes varied from 4.8 to $36.2 \mathrm{ml} / \mathrm{kg}$ (table 2; fig. 2). Since the animals were ventilated in parallel with the same insufflation pressure, tidal volumes can be translated to compliance of the lung/thorax system. Baseline values for compliance are roughly related to gestational age and hence to body weight of the fetuses, but not in a simple linear fashion [39]. In the present study we therefore excluded animals with a body weight $<20 \mathrm{~g}$. Lung gas volume is an equivalent of functional residual capacity which, after successful neonatal adaptation, amounts to about $30 \mathrm{ml} / \mathrm{kg}$ [40]. We feel this parameter carries important information on alveolar stability and, hence, surfactant function. A protocol for experimental evaluation of exogenous surfactants in ventilated newborn animals should, therefore, include assessment of both tidal and end-expiratory lung gas volumes, preferably also histological examination of lung tissue with particular reference to the alveolar expansion pattern.

In conclusion, the complex composition of endogenous surfactant has made it difficult to develop synthetic preparations with optimal properties. However, our data indicate that a synthetic surfactant containing analogues of both SP-B and SP-C, besides increasing tidal volumes, also may stabilize the alveoli during end-expiration and that this type of synthetic surfactants is superior to single-peptide surfactants and may replace surfactant preparations prepared from animal lungs in the near future. 


\section{Acknowledgements}

We are grateful to Bim Linderholm and Marie HaegerstrandBjörkman for expert technical assistance and Robert H. Notter, $M D$, for critical review of the manuscript. This work was supported by the Swedish Research Council, Swedish Heart-Lung
Foundation and Chiesi Farmaceutici, Parma, Italy (B.R., J.J., T.C.) and by grants R01HL092158 from the National Heart, Lung, and Blood Institute and Grant Number R01ES015330 from the National Institute of Environmental Health Sciences (F.J.W., A.J.W.).

\section{References}

1 Halliday H: Recent clinical trials of surfactant treatment for neonates. Biol Neonate 2006;89:323-329.

-2 Haagsman HP, Hogenkamp A, van Eijk M, Veldhuizen EJ: Surfactant collectins and innate immunity. Neonatology 2008;93:288294.

-3 Whitsett JA, Weaver TE: Hydrophobic surfactant proteins in lung function and disease. N Engl J Med 2002;347:2141-2148.

$\checkmark 4$ Curstedt T, Jörnvall H, Robertson B, Bergman T, Berggren P: Two hydrophobic lowmolecular-mass protein fractions of pulmonary surfactant. Characterization and biophysical activity. Eur J Biochem 1987;168: 255-262.

5 Curstedt T, Johansson J, Persson P, Eklund A, Robertson B, Löwenadler B, Jörnvall H: Hydrophobic surfactant-associated polypeptides: SP-C is a lipopeptide with two palmitoylated cysteine residues, whereas SP-B lacks covalently linked fatty acyl groups. Proc Natl Acad Sci USA 1990;87:2985-2989.

-6 Vandenbussche G, Clercx A, Curstedt T, Johansson J, Jörnvall $\mathrm{H}$, Ruysschaert JM: Structure and orientation of the surfactantassociated protein $\mathrm{C}$ in a lipid bilayer. Eur J Biochem 1992;203:201-209.

-7 Pastrana B, Mautone AJ, Mendelsohn R: Fourier transform infrared studies of secondary structure and orientation of pulmonary surfactant SP-C and its effect on the dynamic surface properties of phospholipids. Biochemistry 1991;30:10058-10064.

8 Johansson J, Curstedt T, Jörnvall H: Surfactant protein B: disulfide bridges, structural properties, and kringle similarities. Biochemistry 1991;30:6917-6921.

\9 Liepinsh E, Andersson M, Ruysschaert JM, Otting G: Saposin fold revealed by the NMR structure of NK-lysin. Nat Struct Biol 1997; 4:793-795.

10 Rossmann M, Schultz-Heienbrok R, Behlke J, Remmel N, Alings C, Sandhoff K, Saenger W, Maier T: Crystal structures of human saposins $\mathrm{C}$ and $\mathrm{D}$ : implications for lipid recognition and membrane interactions. Structure 2008;16:809-817.

-11 Johansson J, Nilsson G, Strömberg R, Robertson B, Jörnvall H, Curstedt T: Secondary structure and biophysical activity of synthetic analogues of the pulmonary surfactant polypeptide SP-C. Biochem J 1995;307: 535-541.
12 Luy B, Diener A, Hummel RP, Sturm E, Ulrich WR, Griesinger C: Structure and potential C-terminal dimerization of a recombinant mutant of surfactant-associated protein $\mathrm{C}$ in chloroform/methanol. Eur J Biochem 2004;271:2076-2085.

13 Curstedt T, Johansson J: New synthetic surfactant - how and when? Biol Neonate 2006; 89:336-339.

14 Hawgood S, Ogawa A, Yukitake K, Schlueter M, Brown C, White T, Buckley D, Lesikar D, Benson B: Lung function in premature rabbits treated with recombinant human surfactant protein-C. Am J Respir Crit Care Med 1996;154:484-490

15 Davis AJ, Jobe AH, Häfner D, Ikegami M Lung function in premature lambs and rabbits treated with a recombinant SP-C surfactant. Am J Respir Crit Care Med 1998;157: 553-559.

16 Nilsson G, Gustafsson M, Vandenbussche G, Veldhuizen E, Griffiths WJ, Sjövall J, Haagsman HP, Ruysschaert JM, Robertson B, Curstedt T, Johansson J: Synthetic peptidecontaining surfactants - evaluation of transmembrane versus amphipathic helices and surfactant protein C poly-valyl to poly-leucyl substitution. Eur J Biochem 1998;255:116124.

17 Johansson J, Some M, Linderholm BM, Almlén $\mathrm{A}$, Curstedt $\mathrm{T}$, Robertson B: A synthetic surfactant based on a poly-Leu SP-C analog and phospholipids: effects on tidal volumes and lung gas volumes in ventilated immature newborn rabbits. J Appl Physiol 2003;95: 2055-2063.

18 Revak SD, Merritt TA, Cochrane CG, Heldt GP, Alberts MS, Anderson DW, Kheiter A: Efficacy of synthetic peptide-containing surfactant in the treatment of respiratory distress syndrome in preterm infant rhesus monkeys. Pediatr Res 1996;39:715-724.

19 Merritt TA, Kheiter A, Cochrane CG: Positive end-expiratory pressure during KL4 surfactant instillation enhances intrapulmonary distribution in a simian model of respiratory distress syndrome. Pediatr Res 1995;38:211-217.
20 Gastiasoro-Cuesta E, Alvarez-Diaz FJ, ReySantano C, Arnaiz-Renedo A, LoureiroGonzalez B, Valls-i-Soler A: Acute and sustained effects of lucinactant versus poractant- $\alpha$ on pulmonary gas exchange and mechanics in premature lambs with respiratory distress syndrome. Pediatrics 2006;117: 295-303.

21 Michna J, Jobe AH, Ikegami M: Positive endexpiratory pressure preserves surfactant function in preterm lambs. Am J Respir Crit Care Med 1999;160:634-639.

22 Waring AJ, Walther FJ, Gordon LM, Hernandez-Juviel JM, Hong T, Sherman MA, Alonso C, Alig T, Braun A, Bacon D, Zasadzinski JA: The role of charged amphipathic helices in the structure and function of surfactant protein B. J Pept Res 2005;66:364374.

-23 Gupta M, Hernández-Juviel JM, Waring AJ, Bruni R, Walther FJ: Comparison of functional efficacy of surfactant protein B analogues in lavaged rats. Eur Respir J 2000;16: 1129-1133.

24 Balaraman V, Meister J, Ku TL, Sood SL, Tam E, Killeen J, Uyehara CF, Egan E, Easa D: Lavage administration of dilute surfactants after acute lung injury in neonatal piglets. Am J Respir Crit Care Med 1998;158: $12-17$

25 Walther FJ, Hernández-Juviel JM, Gordon LM, Waring AJ, Stenger P, Zasadzinski JA: Comparison of three lipid formulations for synthetic surfactant with a surfactant protein B analog. Exp Lung Res 2005;31:563579.

26 Spragg RG, Smith RM, Harris K, Lewis J, Häfner D, Germann P: Effect of recombinant SP-C surfactant in a porcine lavage model of acute lung injury. J Appl Physiol 2000;88: 674-681.

27 Hilgendorff A, Reiss I, Ruppert C, Hanfstingl T, Seliger AS, Gunther A, Ebsen M, Gortner L: Positive end-expiratory pressure modifies response to recombinant and natural exogenous surfactant in ventilated immature newborn rabbits. Biol Neonate 2006; 90:210-216.

28 Almlén A, Stichtenoth G, Linderholm B, Haegerstrand-Björkman M, Robertson B, Johansson J, Curstedt T: Surfactant proteins $\mathrm{B}$ and $\mathrm{C}$ are both necessary for alveolar stability at end-expiration in premature rabbits with respiratory distress syndrome. J Appl Physiol 2008;104:1101-1108. 
-29 Waring A, Walther F, Gordon L, HernandezJuviel J, Hong T, Sherman M, Alonso C, Alig T, Braun A, Bacon D, Zasadzinski J: The role of charged amphipathic helices in the structure and function of surfactant protein B. Pept Res 2005;66:364-374.

>30 Sarker M, Waring AJ, Walther FJ, Keough KM, Booth V: Structure of Mini-B, a functional fragment of surfactant protein $B$, in detergent micelles. Biochemistry 2007;46: 11047-11056.

-31 Scherle W: A simple method for volumetry of organs in quantitative stereology. Mikroskopie 1970;26:57-60.

>32 Berggren P, Rigaut JP, Curstedt T, Robertson B: Computerized image analysis of lung expansion patterns in surfactant-treated immature newborn rabbits. Respir Physiol 1999; 115:45-53.
33 Lindahl E, Hess B, van der Spoel D: GROMACS 3.0: a package for molecular simulation and trajectory analysis. J Mol Model 2001;7:306-317.

34 Curstedt T, Johansson J, Barros-Söderling J, Robertson B, Nilsson G, Westberg M, Jörnvall $\mathrm{H}$ : Low-molecular-mass surfactant protein type 1 . The primary structure of a hydrophobic 8-kDa polypeptide with eight half-cystine residues. Eur J Biochem 1988; 172:521-525.

35 Johansson J, Curstedt T, Robertson B, Jörnvall $\mathrm{H}$ : Size and structure of the hydrophobic low molecular weight surfactant-associated polypeptide. Biochemistry 1988;27:35443547.

36 Walther FJ, Waring AJ, Hernandez-Juviel JM, Gordon LM, Schwan AL, Jung CL, Chang Y, Wang Z, Notter RH: Dynamic surface activity of a fully synthetic phospholipase-resistant lipid/peptide lung surfactant. PLoS One 2007;2:e1039.
7 Dhand R, Young J, Krishnasamy S, Possmayer F, Gross NJ: Influence of phospholipid composition on the properties of reconstituted surfactants. Lung 1999;177:127-138.

38 Charon A, Taeusch W, Fitzgibbon C, Smith GB, Treves ST, Phelps DS: Factors associated with surfactant treatment response in infants with severe respiratory distress syndrome. Pediatrics 1989;83:348-354.

39 Kobayashi T, Shido A, Nitta K, Inui S, Ganzuka M, Robertson B: The critical concentration of surfactant in fetal lung liquid at birth. Respir Physiol 1990;80:181-192.

40 Strang LB: Fetal lung liquid: secretion and reabsorption. Physiol Rev 1991;71:991-1016. 